\title{
Stimulation of long-term ammonium nitrogen deposition on methanogenesis by Methanocellaceae in a coastal wetland
}

\author{
Xiao Leilei ${ }^{\mathrm{a}, \mathrm{b}, 1}$, Xie Baohua ${ }^{\mathrm{b}, 1}$, Liu Jinchao ${ }^{\mathrm{a}, \mathrm{c}}$, Zhang Hongxia ${ }^{\mathrm{a}, \mathrm{c}}$, Han Guangxuan ${ }^{\mathrm{b}}$, \\ Wang Oumei ${ }^{\mathrm{d}, *}$, Liu Fanghua ${ }^{\mathrm{a}, \mathrm{b}, * * *}$ \\ a Key Laboratory of Coastal Biology and Biological Resources Utilization, Yantai Institute of Coastal Zone Research, Chinese Academy of Sciences, Yantai 264003, China \\ ${ }^{\mathrm{b}}$ Key Laboratory of Coastal Environmental Processes and Ecological Remediation, Yantai Institute of Coastal Zone Research, Chinese Academy of Sciences, Yantai 264003, China \\ c University of Chinese Academy of Sciences, Beijing 100049, China \\ d Binzhou Medical University, Yantai, China
}

\section{H I G H L I G H T S}

- The deposition of both ammonium and nitrate nitrogen on methane emission was tested.

- Deposition of ammonium nitrogen accelerated methane emissions all year round.

- Ammonium nitrogen converted Yellow River Delta to a $\mathrm{CH}_{4}$ source during the dry season.

- Methanocellaceae increased in abundance in response to ammonium nitrogen deposition.

- Nitrate nitrogen deposition did not affect methane flux significantly.

\section{A R T I C L E I N F O}

\section{Article history:}

Received 11 February 2017

Received in revised form 30 March 2017

Accepted 30 March 2017

Available online 5 April 2017

Editor: Elena Paoletti

\section{Keywords:}

Atmospheric nitrogen deposition

Ammonium and nitrate nitrogen

Methane flux

Methanogens

Dry-wet alternate

Coastal wetland
G R A P H I C A L A B S T R A C T

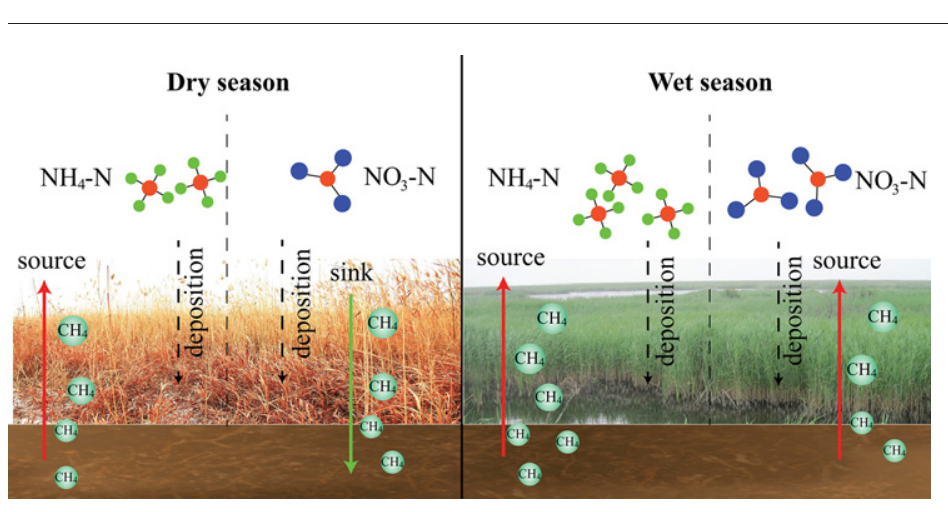

\begin{abstract}
A B S T R A C T
Atmospheric nitrogen deposition caused by human activities has been receiving much attention. Here, after long-term simulated ammonium and nitrate nitrogen deposition $\left(\mathrm{NH}_{4} \mathrm{Cl}, \mathrm{KNO}_{3}\right.$, and $\left.\mathrm{NH}_{4} \mathrm{NO}_{3}\right)$ in the Yellow River Delta (YRD), a sensitive coastal wetland ecosystem typified by a distinct wet and dry season, methane fluxes were measured, by adopting a closed static chamber technique. The results showed that deposition of ammonium nitrogen accelerated methane emissions all year round. Ammonium nitrogen deposition transformed the YRD from a methane sink into a source during the dry season. Methanocellaceae is the only methanogen with increased abundance after the application of $\mathrm{NH}_{4} \mathrm{Cl}$ and $\mathrm{NH}_{4} \mathrm{NO}_{3}$, which promoted methane emissions, during the wet season. The findings suggested that Methanocellaceae may facilitate methane emissions in response to increased ammonium nitrogen deposition. Other methanogens might have profited from ammonium supplementation, such as Methanosarcinaceae. Deposition of nitrate nitrogen did not affect methane flux significantly. To the best of our knowledge, this study is the first to show that Methanocellaceae may be responsible for methane production in coastal wetland system. This study highlights the significant effect of ammonium nitrogen and slight effect of nitrate nitrogen on methane emission in the YRD and it will be helpful to understand the microbial mechanism responding to increased nitrogen deposition in the sensitive coastal wetland ecosystem.
\end{abstract}

(C) 2017 Elsevier B.V. All rights reserved.

* Correspondence to: O. Wang, Binzhou Medical University, 346 Guanhai Road, Laishan District, Yantai, Shandong 264003, China.

** Correspondence to: F. Liu, Yantai Institute of Coastal Zone Research, 17 Chunhui Road, Laishan District, Yantai, Shandong 264003, China.

E-mail addresses: omwang@aliyun.com (O. Wang), fhliu@yic.ac.cn (F. Liu).

1 Leilei Xiao and Baohua Xie have contributed equally to this work. 


\section{Introduction}

Atmospheric nitrogen deposition caused by human activities has been receiving much attention (Kanakidou et al., 2016). The annual anthropogenic input of nitrogen in ecosystems has increased tenfold over the past 150 years, and it is predicted to be $2-3$ times the current level in the 2050s (Sutton and Bleeker, 2013). Impacts by nitrogen deposition occur on a global scale, especially in terrestrial ecosystems (Asner et al., 2001; Matson et al., 2002). Meanwhile, nitrogen deposition affects various ecological types, such as marine (Zhang et al., 2010), forest (Zhang et al., 2016), grassland (Gomez-Casanovas et al., 2016), lake (Hobbs et al., 2016), and coastal (Pakeman et al., 2016) systems. Understanding of how nitrogen deposition affects coastal wetlands is limited, although this type of ecosystem is vulnerable to environmental change (Wolters et al., 2016).

The nitrogen cycle is closely coupled to the carbon cycle (Gruber and Galloway, 2008). The tight coupling between nitrogen enrichment and methanogenesis has evoked numerous studies assessing the application of nitrogen fertilizers and nitrogen deposition on methane emission (Bodelier, 2011). Liu and Greaver (2009) undertook meta-analyses of studies on wetlands as well as upland soils with treated and control sites which were comparable in terms of climatic, soil, and vegetation conditions. The conclusion was that $\mathrm{N}$-enrichment of ecosystems in general would enhance methane emission because of lowering of consumption and increase of production. It is well known that effects of ammonium and nitrate nitrogen were different, and even the same type had distinct impacts on different regions (Bodelier, 2011). Therefore, it is of great significance to comprehensively study the effects of deposition of different types of nitrogen on the methane flux from vulnerable ecological regions.

All biogenic methane is produced by methanogenic archaea (Angel et al., 2012). Nitrogen deposition can change microbial community structure and function to influence methane production (Sinsabaugh et al., 2015), so understanding the response of methanogenic archaea may be the key to clarify the effect of different types of nitrogen enrichment on methane emission.

Atmospheric nitrogen deposition is one of the major nitrogen sources in the coastal zone of Yellow River Delta (YRD) (Ning et al., 2015), which has been shown to be a region of low adaptability and high environmental vulnerability (Wolters et al., 2016), typified by a distinct wet and dry season. Therefore, YRD is a natural system ideally suited to study the effect of increased nitrogen deposition on methane emissions. In this study, after long-term simulated atmospheric deposition of ammonium and nitrate nitrogen $\left(\mathrm{NH}_{4} \mathrm{Cl}, \mathrm{KNO}_{3}\right.$, and $\left.\mathrm{NH}_{4} \mathrm{NO}_{3}\right)$ in the YRD, methane fluxes were determined to clarify whether there are different effects of ammonium and nitrate nitrogen on methane emission and the potential microbial mechanism responding to increased nitrogen deposition in the sensitive coastal wetland ecosystem.

\section{Materials and methods}

\subsection{Sites, vegetation and environmental conditions}

The study site $\left(37^{\circ} 45^{\prime} 46^{\prime \prime} \mathrm{N}, 118^{\circ} 58^{\prime} 40^{\prime \prime} \mathrm{E}\right)$ in the YRD (Fig. 1 ) has a temperate semi-humid continental monsoon climate (Yu et al., 2011). The average annual precipitation is $530-630 \mathrm{~mm}$, concentrated mostly in summer. It is typified by distinct wet (in general, July to September) and dry (in general, October to June) seasons and remains inundated throughout the wet season. This research site is dominated by Phragmites australis interspersed with Suaeda heteroptera Kitag. Fluvo-aquic soil and saline soil are the main soil types and the soil texture is sandy loam.

\subsection{Simulated nitrogen deposition}

The description of simulated nitrogen deposition can be found elsewhere (Zhu et al., 2013). Briefly, the experiments (established in 2012)

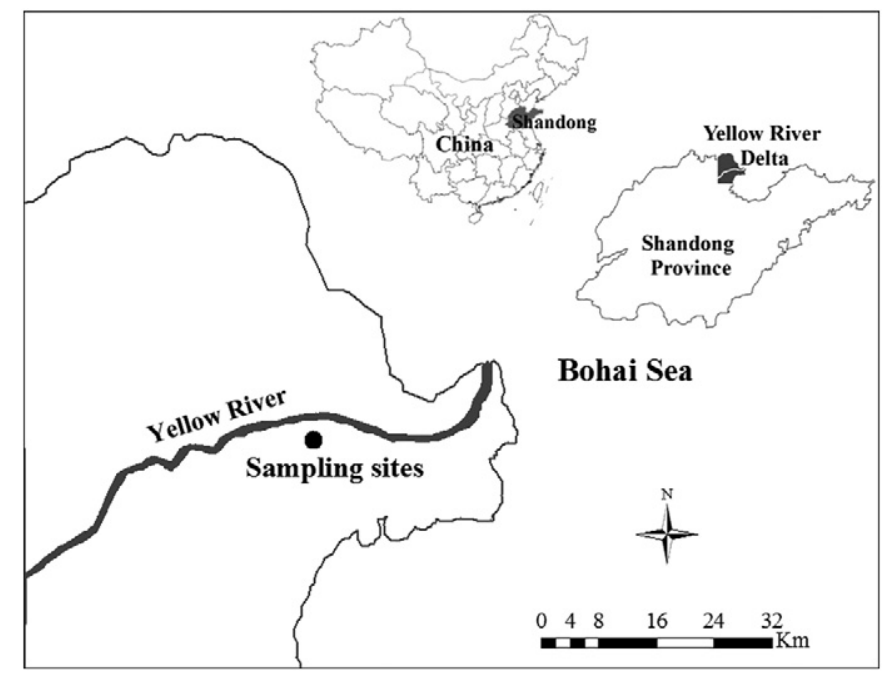

Fig. 1. Location of sampling sites in the Yellow River Delta.

were designed with three treatments, $\mathrm{NH}_{4} \mathrm{Cl}, \mathrm{KNO}_{3}$, and $\mathrm{NH}_{4} \mathrm{NO}_{3}$. Each treatment had four replicated plots. For ammonium and nitrate nitrogen $\left(\mathrm{NH}_{4} \mathrm{Cl}\right.$ and $\left.\mathrm{KNO}_{3}\right)$, each plot $(8 \mathrm{~m} \times 6 \mathrm{~m})$ receives nitrogen at a rate of $50 \mathrm{~kg} \mathrm{~N} \mathrm{ha}^{-1} \mathrm{yr}^{-1}$. For $\mathrm{NH}_{4} \mathrm{NO}_{3}$ treatment, $100 \mathrm{~kg} \mathrm{~N} \mathrm{ha}^{-1} \mathrm{yr}^{-1}$ is applied. These chemical reagents are dissolved in water and evenly sprayed over the area of interest: this process was carried out since 2012. The control treatment area is sprayed using pure water without any extra nitrogen source. These operations are performed once a month.

\subsection{Methane flux determination}

Boardwalks were installed in each plot to reduce soil disturbance during measurement. Methane fluxes were manually measured using the static chamber method as described by Wang and Wang (2003) and Zheng et al. (2008). A transparent Plexiglas ${ }^{\circledR}$ chamber $(120 \mathrm{~cm}$ high) was placed on a stainless steel base $(50 \mathrm{~cm} \times 50 \mathrm{~cm})$ which was installed before the start of the experiment. A small fan was installed inside the chamber to mix the headspace gas and a rubber septum inserted into the chamber was used to collect gas samples. Five gas samples from the chamber headspace were collected at 15 min intervals with a syringe after enclosure of the chamber. The collected gas sample $(50 \mathrm{ml}$ ) was immediately transferred into a 12-ml vacuum borosilicate vials (Labco, UK). The gas samples were analyzed with a gas chromatograph (GC) (Agilent 7890A, USA) equipped with a flame ionization detector and an automated flow-injection apparatus. Methane flux rates were calculated from the linear increase of methane mixing ratio in chambers, according to the description by Wang (2001). Briefly, that equation can be expressed as $\mathrm{F}=\rho \frac{\mathrm{V}}{\mathrm{A}} \frac{\mathrm{P}}{\mathrm{P}_{0}} \frac{\mathrm{T}_{0}}{\mathrm{~T}} \frac{\mathrm{d} \mathrm{C}_{\mathrm{t}}}{\mathrm{dt}}$, where $\mathrm{F}$ is the $\mathrm{CH}_{4}$ flux rate, $\rho$ is the $\mathrm{CH}_{4}$ density at standard temperature and pressure, $\mathrm{V}$ is the volume of the chamber, $A$ is the bottom surface area of the chamber, $\mathrm{P}$ and $\mathrm{T}$ are the air pressure and temperature in the chamber respectively, $T_{0}$ is $273.15 \mathrm{~K}$ and $\mathrm{P}_{0}$ is $101.325 \mathrm{kPa}, \frac{\mathrm{d} \mathrm{C}_{\mathrm{t}}}{\mathrm{dt}}$ is average change rate of methane concentration. For the description of methane flux, if the region is a methane sink (methane flows from the atmosphere to below ground), the value is negative (-). If the region is a source of methane (methane flows from below ground to the atmosphere), the value is positive $(+)$. If needed, $\sim 1.5 \%(\mathrm{v} / \mathrm{v}$ of the headspace) difluoromethane $\left(\mathrm{CH}_{2} \mathrm{~F}_{2}\right)$ was added into the chambers to specifically inhibit methane oxidation before collecting the gas (Kruger et al., 2001). Then the gas was sampled and analyzed as above. 


\subsection{Pore water profiles of methane concentration}

Soil pore water samples were collected using self-constructed samplers after about 15 days of fertilization. Those samplers were installed underground when the experimental area for nitrogen deposition was laid. The measurement depths were set to 30 and $60 \mathrm{~cm}$. The bottom of each PVC tube was covered with a soil-pore water separator to prevent contamination, and the top of tube was sealed with rubber septa. The system is closed, so exogenous and man-made pollution can be avoided. The sampling process is shown in Fig. S1. Briefly, a customized syringe was used to drain the stored water and evacuate the PVC tube as best possible. Twenty four hours later, pore water, which can seep into the PVC tube, was collected in a syringe (right) when extra pressure was provided from the customized syringe from the other port of the device (left). Vacuum tubes (12-ml) were used to store collected pore water (6 ml). After manual shaking, a $200 \mu \mathrm{l}$ gas sample was taken from the headspace of each tube for methane analysis with a GC (Agilent $7820 \mathrm{~A}$, USA) equipped with a flame ionization detector. Nitrogen gas was used as the carrier gas at a flow rate of $20 \mathrm{ml} \mathrm{min}^{-1}$.

\subsection{Soil sampling and nitrogen analysis}

Soil was sampled during the wet (Sep. 2015) and dry seasons (Dec. 2015) using stainless steel corers with an inner diameter of $4 \mathrm{~cm}$ after about 15 days of fertilization. At least six soil cores were collected within a $6 \mathrm{~m} \times 8 \mathrm{~m}$ area. Cores were sectioned at $10 \mathrm{~cm}$ intervals to a depth of $50 \mathrm{~cm}$. Some of the soil was stored at $-20^{\circ} \mathrm{C}$ for microbial diversity analysis. The remainder of the soil samples were air dried, sieved ( $2 \mathrm{~mm}$ mesh size), and stored at room temperature. Ammonium and nitrate nitrogen were tested in all five soil layers using a flow-injection autoanalyzer (Seal-Branlubbe AA3, Germany) shown in Tables 1 and 2 , respectively.

\subsection{Microbial diversity analysis}

Before deoxyribonucleic acid (DNA) extraction, soil core samples were thawed slightly. Total genomic DNA was extracted using a FastDNA ${ }^{\text {TM }}$ SPIN Kit for soil (MP Biomedicals, Santa Ana, CA), and the details can be found in the instructions supplied with the kit. Equal amounts of DNA extracted from five soil layers of different cores of four plots were mixed. Polymerase chain reaction (PCR) amplification of $16 \mathrm{~S}$ ribosomal ribonucleic acid (rRNA) genes was performed using bacterial primers (Ba338f and Ba806r) and archaeal primers (Ar515f and Ar907r). Illumina-Solexa sequencing platform was applied for the determination of bacteria and archaea diversity. Raw reads, low quality sequences, clustering operational taxonomic units (OTUs), and taxonomic classifications were processed as before (Zheng et al., 2015). Briefly, trimmomatic (Bolger et al., 2014) and FLASH (Reyon et al., 2012) were used to process raw reads of 16S rRNA gene for merging the paired-end reads, followed by filtering low quality sequences. Then, USEARCH was employed to remove chimeric sequences (Edgar et al., 2011). Qualified sequences were clustered into operational taxonomic units (OTUs) using CD-HIT. The most abundant sequence was selected as a representative sequence for each OTU. The taxonomy of each OTU was phylogenetically assigned to taxonomic classifications using

Table 1

Ammonium nitrogen content ( $\mathrm{mg} \mathrm{kg}^{-1}$ ) sampled during the wet season (Sep. 2015).

\begin{tabular}{lllll}
\hline Soil profile $(\mathrm{cm})$ & Control & $\mathrm{NH}_{4} \mathrm{Cl}$ & $\mathrm{KNO}_{3}$ & $\mathrm{NH}_{4} \mathrm{NO}_{3}$ \\
\hline $0-10$ & $0.975 \pm 0.05^{\mathrm{a}}$ & $1.50 \pm 0.141$ & $1.23 \pm 0.416$ & $1.97 \pm 0.923$ \\
$10-20$ & $0.65 \pm 0.264$ & $1.533 \pm 0.351$ & $0.775 \pm 0.320$ & $1.625 \pm 0.499$ \\
$20-30$ & $0.675 \pm 0.330$ & $1.40 \pm 0.101$ & $1.47 \pm 0.573$ & $1.425 \pm 0.591$ \\
$30-40$ & $0.925 \pm 0.403$ & $0.875 \pm 0.126$ & $1.50 \pm 0.294$ & $1.400 \pm 0.141$ \\
$40-50$ & $1.60 \pm 0.818$ & $0.975 \pm 0.222$ & $1.02 \pm 0.210$ & $1.0264 \pm 0.417$ \\
\hline
\end{tabular}

a The values are mean \pm standard deviation, which are calculated based on three or four replicates.
Table 2

Nitrate nitrogen content ( $\mathrm{mg} \mathrm{kg}^{-1}$ ) sampled during the wet season (Sep. 2015).

\begin{tabular}{lllll}
\hline Soil profile $(\mathrm{cm})$ & Control & $\mathrm{NH}_{4} \mathrm{Cl}$ & $\mathrm{KNO}_{3}$ & $\mathrm{NH}_{4} \mathrm{NO}_{3}$ \\
\hline $0-10$ & $2.22 \pm 0.493^{\mathrm{a}}$ & $2.82 \pm 0.454$ & $2.929 \pm 0.338$ & $2.67 \pm 0.509$ \\
$10-20$ & $2.25 \pm 0.308$ & $1.85 \pm 0.068$ & $1.953 \pm 0.558$ & $2.40 \pm 0.159$ \\
$20-30$ & $1.95 \pm 0.204$ & $1.40 \pm 0.524$ & $1.350 \pm 0.357$ & $1.84 \pm 0.358$ \\
$30-40$ & $1.11 \pm 0.157$ & $1.06 \pm 0.206$ & $1.905 \pm 0.469$ & $1.43 \pm 0.356$ \\
$40-50$ & $1.19 \pm 0.373$ & $0.760 \pm 0.817$ & $1.432 \pm 0.860$ & $0.915 \pm 0.016$ \\
\hline
\end{tabular}

a The values are mean \pm standard deviation, which are calculated based on three or four replicates.

ribosomal database project Classifier (Wang et al., 2007) and the Greengenes database (DeSantis et al., 2006). For the analysis of the sequences, changes in relative abundance (CRA) of bacteria and archaea populations at the family level during the wet season, and CRA of archaea populations at the family level during the dry and wet seasons, were calculated. CRA is the ratio of microbial abundance of nitrogen deposition to that of control. If the value of CRA is smaller than 1.0, i.e., the microbial abundance of nitrogen deposition is smaller than that of control, CRA is the ratio of microbial abundance of control to nitrogen deposition multiplied by -1 .

\subsection{Statistical analysis}

All statistical analyses were performed with SPSS 19.0 (SPSS Inc., Chicago, USA) and Origin 8.0 (Origin Lab Corporation, USA) software. A one-way analysis of variance with Tukey's test was used to analyze the significance of the effects of nitrogen fertilization on the seasonal amounts of pore water methane concentration. The mean (along with the standard deviation) was calculated based on at least three replicates. Redundancy analysis (RDA) was conducted to reveal the relationships between the soil microbial community and measured environmental variables. RDA was performed using CANOCO 4.5 for Windows.

\section{Results}

\subsection{Effects of nitrogen deposition on methane emission during the dry season}

Overall, both ammonium and nitrate nitrogen deposition had a relatively weak effect on methane emission during the dry season (Fig. 2A). The flux from all four groups was from -50 to $100 \mu \mathrm{g} \mathrm{C} \mathrm{m} \mathrm{m}^{-2} \mathrm{~h}^{-1}$. If outliers were ignored, the control plot and the plot with nitrate deposition $\left(\mathrm{KNO}_{3}\right)$ act as a methane sink (from May to June in 2015). $\mathrm{NH}_{4} \mathrm{NO}_{3}$ treatment showed the same effect. On the contrary, the median value of the methane flux was positive with $\mathrm{NH}_{4} \mathrm{Cl}$ deposition, i.e., nitrogen deposition of ammonium nitrogen enhanced methane emissions.

To test the robustness of the results for different years, the methane fluxes were repeated during May 2016 (Fig. $2 \mathrm{~B}, \mathrm{CH}_{2} \mathrm{~F}_{2}(-)$ ). As in 2015, $\mathrm{NH}_{4} \mathrm{Cl}$ treatment caused the experimental sites become a methane source in 2016. The methane flux was about $49.5 \mu \mathrm{g} \mathrm{C} \mathrm{m}{ }^{-2} \mathrm{~h}^{-1}$. It was comparable to that in 2015 of $23.54 \mu \mathrm{C} \mathrm{m}^{-2} \mathrm{~h}^{-1}$. The effects of methane flux with nitrate-containing solutions $\left(\mathrm{KNO}_{3}\right.$ and $\left.\mathrm{NH}_{4} \mathrm{NO}_{3}\right)$ were consistent with those found in 2015. To explore the effect of nitrogen deposition on net methane production, $\mathrm{CH}_{2} \mathrm{~F}_{2}$ was added into the chamber. The results showed that $\mathrm{KNO}_{3}$ and $\mathrm{NH}_{4} \mathrm{NO}_{3}$ did not promote methane emission (Fig. 2B, black column). Alternatively, methane flux increased with ammonium nitrogen application $(p<0.05)$. These results suggest that methane emissions can be increased by deposition of ammonium nitrogen during the dry season.

Ammonium nitrogen deposition slightly increased methane concentration of pore water (Fig. 2C). Compared with control, ammonium nitrogen deposition showed an increase in methane concentration at $60 \mathrm{~cm}$ depth of pore water $(p<0.05)$, with the maximum methane concentration being approximately $0.24 \mu \mathrm{mol} / \mathrm{L}$. 

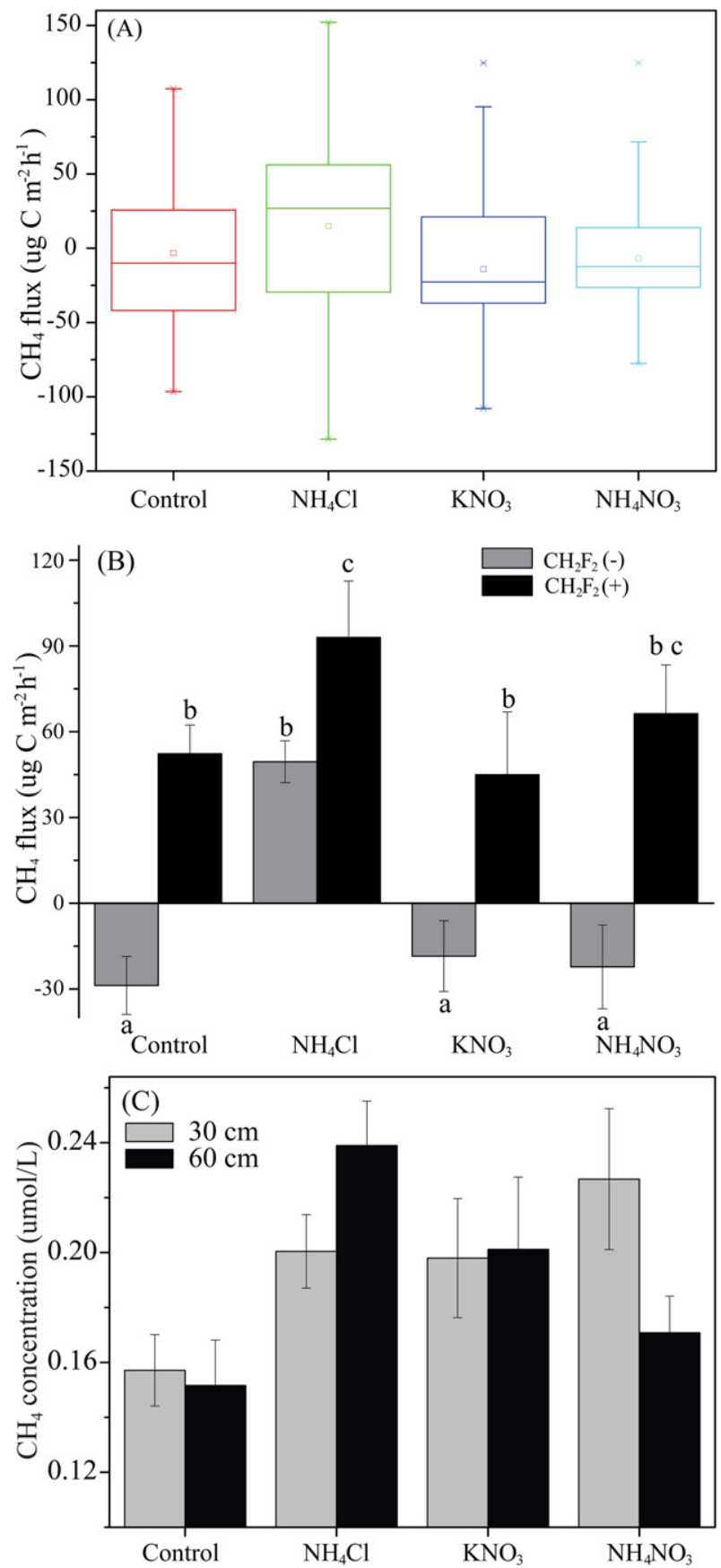

Fig. 2. Methane emission during the dry season. Methane flux in 2015 (A); methane flux (gray) and net methane production (black) in 2016 (B), methane concentration of pore water sampled at the depths of 30 and $60 \mathrm{~cm}$ in 2015 (C). (-) represents a methane sink, and $(+)$ represents a methane source. The outliers are shown in the form of asterisks. The columns and bars represent mean + standard deviation. A one-way analysis of variance with Tukey's test was used to analyze the level of significance of the effects of nitrogen deposition on methane flux and net methane production in 2016. The different letters above the error bars mean significant differences $(p<0.05, \mathrm{n}=3)$.

\subsection{Effects of simulated nitrogen deposition on methane emission during the wet season}

The control, and all three types of nitrogen deposition, showed methane flux from below ground to atmosphere during the wet season (from August to September 2015) (Fig. 3A), i.e., the YRD coastal wetland was source of atmospheric methane when precipitation increased. The treatments of $\mathrm{NH}_{4} \mathrm{Cl}$ and $\mathrm{NH}_{4} \mathrm{NO}_{3}$ accelerated methane emission. Analysis of the box plot to be seen that the outlier truncation point reached $942.4 \mu \mathrm{g} \mathrm{C} \mathrm{m}{ }^{-2} \mathrm{~h}^{-1}$ with addition of $\mathrm{NH}_{4} \mathrm{NO}_{3}$. The effect of $\mathrm{KNO}_{3}$ seemed relatively weak and outlier truncation point was $272.04 \mu \mathrm{g} \mathrm{C} \mathrm{m}{ }^{-2} \mathrm{~h}^{-1}$.

The methane concentration in the pore water increased with nitrogen deposition (Fig. 3B). It seemed that the impact of $\mathrm{NH}_{4} \mathrm{NO}_{3}$ was most obvious, followed by $\mathrm{NH}_{4} \mathrm{Cl}$. The results were consistent with the idea that methane emissions were promoted by ammonium nitrogen deposition, and agreed with measured ammonium nitrogen contents.

\subsection{Contents of ammonium and nitrate nitrogen after simulated nitrogen deposition}

Effects of nitrogen deposition on methane emission were relatively weak during the dry season. Two treatments containing ammonium nitrogen $\left(\mathrm{NH}_{4} \mathrm{Cl}\right.$ and $\left.\mathrm{NH}_{4} \mathrm{NO}_{3}\right)$ stimulated methane emission during the wet season, so nitrogen contents were measured to explore the relationship between in situ concentration of ammonium/nitrate nitrogen and methane emissions during that time. Compared with control, content of ammonium nitrogen increased with the addition of $\mathrm{NH}_{4} \mathrm{Cl}$ and $\mathrm{NH}_{4} \mathrm{NO}_{3}$. Application of $\mathrm{NH}_{4} \mathrm{NO}_{3}$ came with a higher ammonium nitrogen content followed by $\mathrm{NH}_{4} \mathrm{Cl}$ (Tables 1 and S4). Using of $\mathrm{KNO}_{3}$ also increased the ammonium nitrogen content to some extent. Application of
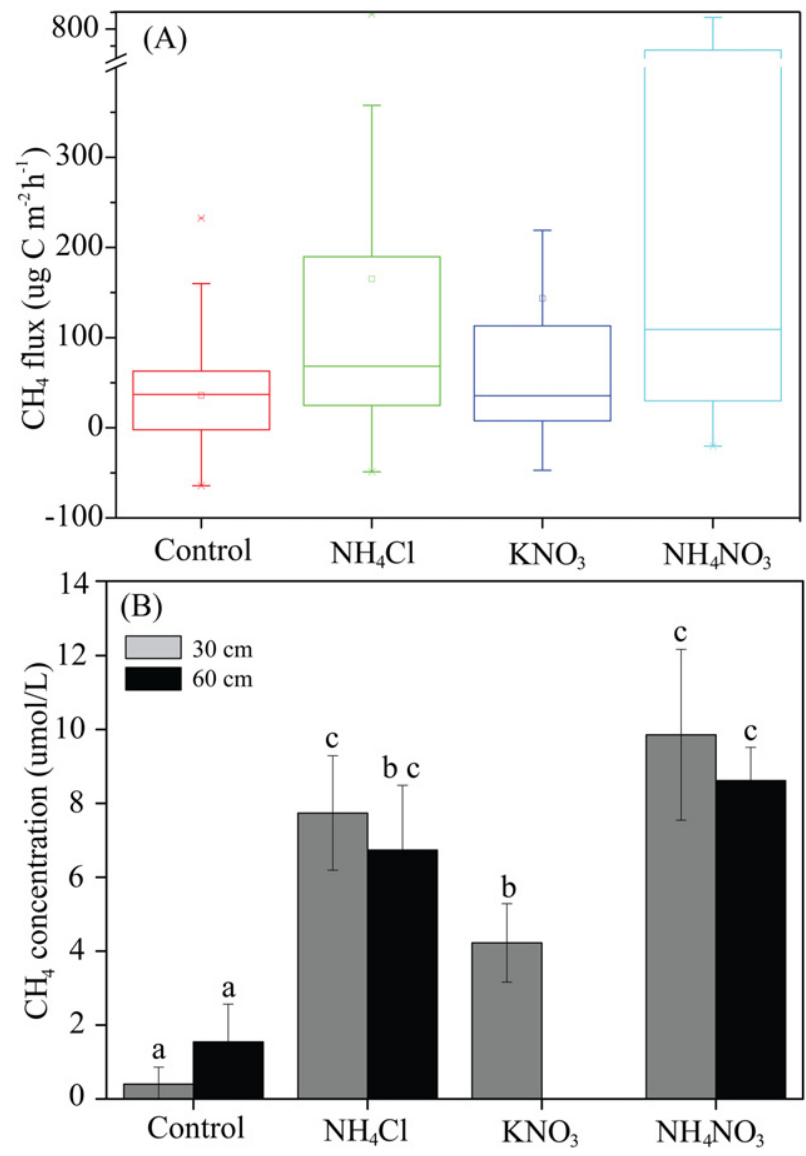

Fig. 3. Methane emissions during the wet season. Methane flux in 2015 (A); methane concentration of pore water sampled at depths of 30 and $60 \mathrm{~cm}$ in 2015 (B). We failed to get pore water data for $\mathrm{KNO}_{3}$ treatment at depth of $60 \mathrm{~cm}$. (-) represents a methane sink, and $(+)$ represents a methane source. The outliers are shown in the form of asterisks, and some outliers, which are 10 -fold greater than the median value, are not shown under the treatment of $\mathrm{NH}_{4} \mathrm{NO}_{3}$. The columns and bars represent mean + standard deviation. A one-way analysis of variance with Tukey's test was used to analyze the level of significance of the effects of nitrogen deposition on pore water methane concentration. The different letters above the error bars mean significant differences $(p<0.05, \mathrm{n}=3)$. 
$\mathrm{KNO}_{3}$ and $\mathrm{NH}_{4} \mathrm{NO}_{3}$ improved the nitrate nitrogen content, but simulated ammonium deposition did not increase the nitrate nitrogen content (Tables 2 and S4).

\subsection{Changes of bacterial diversity and abundance in response to nitrogen deposition during the wet season}

To avoid false positive as far as possible, only the genes with an abundance $>0.3 \%$ (top ten) were presented (Table S1). The results showed that only abundances of Geobacillus and Clostridium increased under the influence of three nitrogen treatments. The treatments containing ammonium nitrogen $\left(\mathrm{NH}_{4} \mathrm{Cl}\right.$ and $\left.\mathrm{NH}_{4} \mathrm{NO}_{3}\right)$ decreased the abundances of Flavobacterium, Bacillus, Gillisia, Marinobacter, and Desulfosarcina. This was consistent with the analysis of the RDA results (Fig. 4B). There was a high correlation between Geobacillus/Clostridium and ammonium nitrogen. It should be noted that nitrate nitrogen appeared to have a similar influence to that of ammonium nitrogen on bacterial diversity (Fig. 4B).
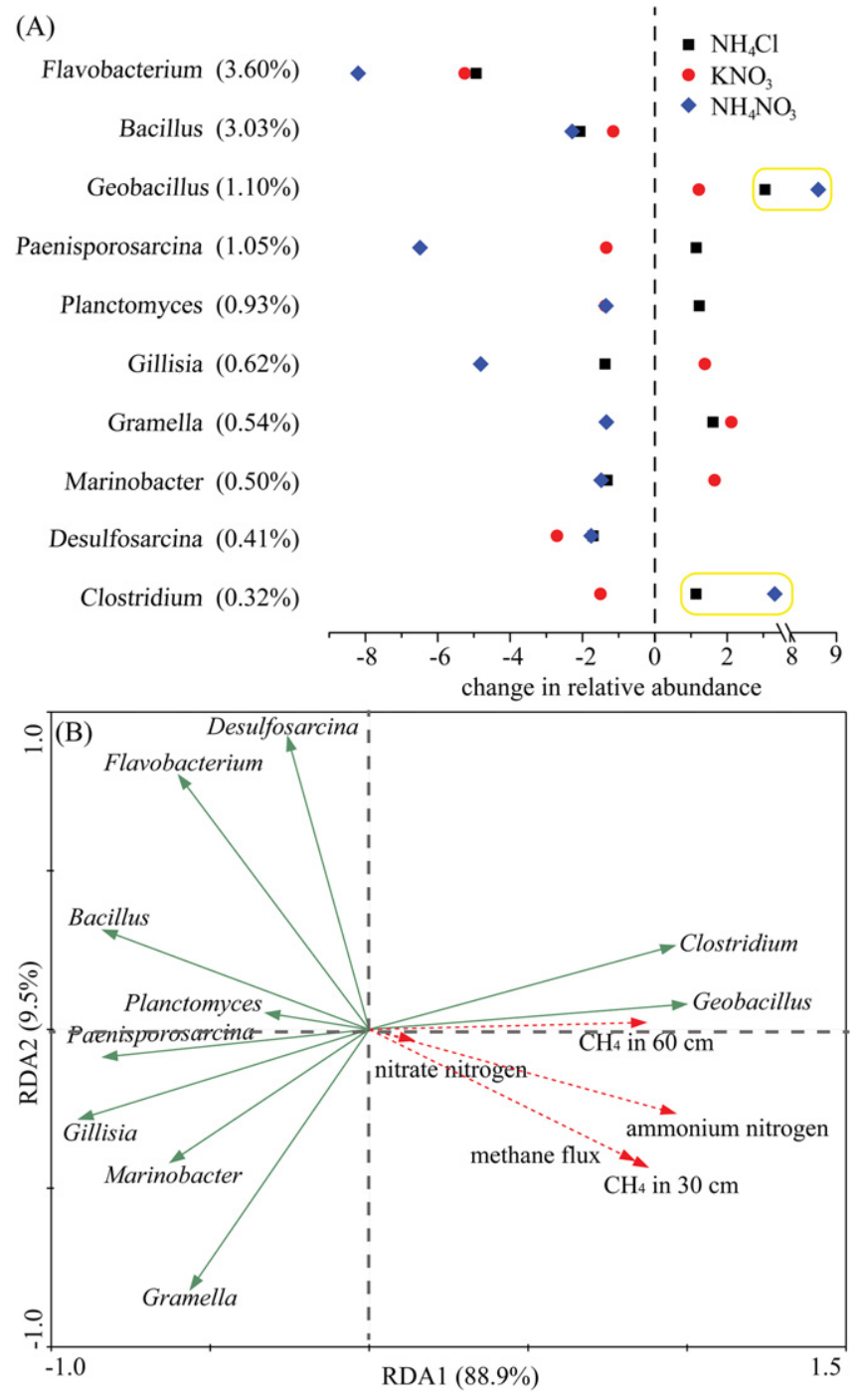

Fig. 4. Changes in relative abundance (CRA) of bacteria populations at family level after the addition of three types of nitrogen during the wet season (A). Redundancy analysis based on the relative abundance of bacterial family, and selected environmental, variables (Table S4) for the control and three kinds of nitrogen treatments. The percentage values behind the taxonomic names in graph $(\mathrm{A})$ indicated relative abundance in control treatment. CRA is the ratio of microbial abundance of nitrogen deposition to that of control.
3.5. Archaea diversity and abundance affected by simulated nitrogen deposition

Soil moisture affects methane emission, so methanogens were tested during the wet and dry seasons. Precipitation affected abundances of archaea at family level, but the community compositions did not change accordingly (Figs. 5A and S2, Tables S2 and S3). The abundance of Nitrososphaeraceae increased more than two-fold from the dry to wet season. The abundance of Crenarchaeaceae and Halobacteriaceae decreased. Especially in the case of for Halobacteriaceae, the reduction, which was from $20.1 \%$ to $6.9 \%$, was significant. For methanogenic archaea, the abundance of predominant methanogen, Methanomassiliicoccaceae, underwent a remarkable decrease from the dry to wet season, from $1.51 \%$ to $0.76 \%$. Nitrogen deposition boosted Methanocellaceae abundance during the dry season (Table S2). During the wet season, Methanocellaceae abundance improved slightly (Fig. 5A and Table S3). The analysis of RDA suggested that abundance of Methanocellaceae and ammonium nitrogen content were significantly positively correlated (Fig. 5B). In contrast, the nitrate nitrogen content did not appear to be an environmental factor that increased Methanocellaceae abundance. It was a near-perfect match between ammonium nitrogen content and methane concentrations of pore water suggesting that pore water methane concentration may be significantly affected by ammonium nitrogen.
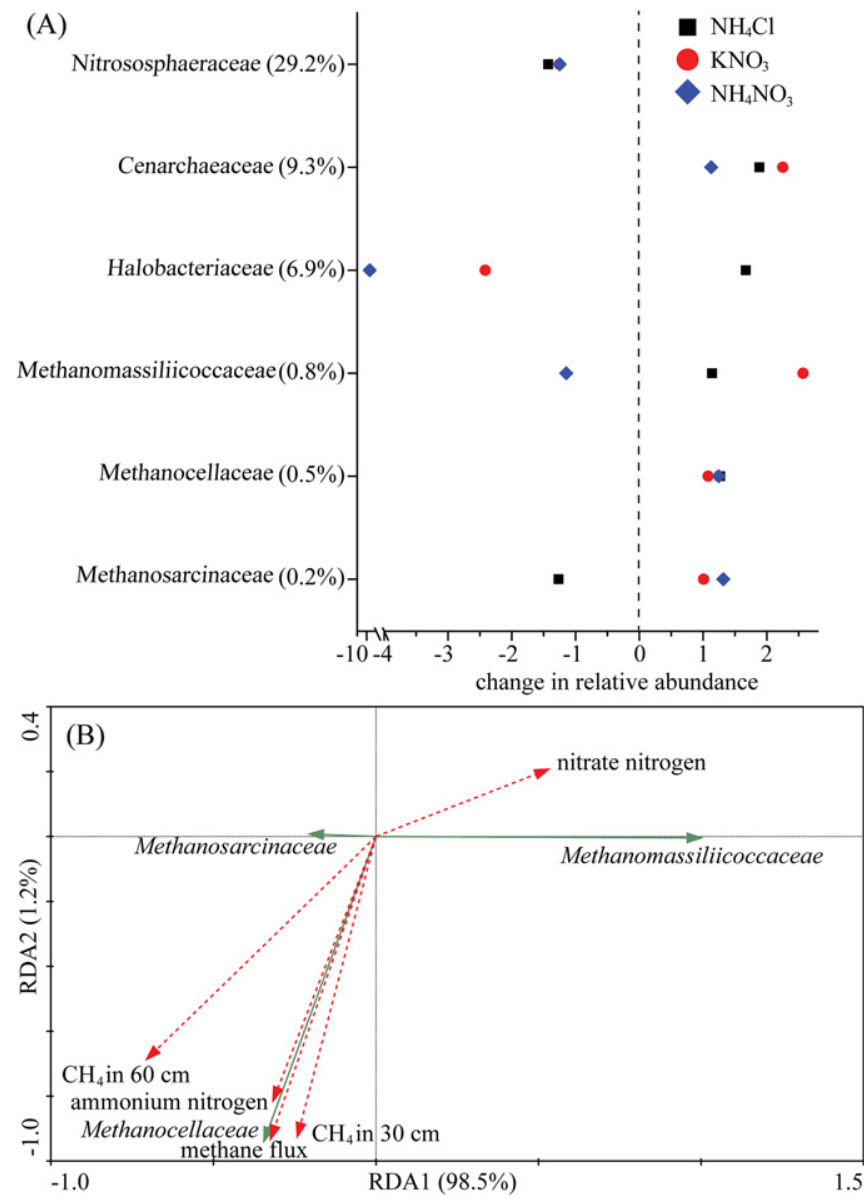

Fig. 5. Changes in relative abundance (CRA) of archaea populations at family level after the addition of three types of nitrogen during the wet season (A). Redundancy analysis based on the relative abundance of archaea at family level and selected environmental variables (Table S4) for the four treatments. The percentage values behind the taxonomic names in graph (A) indicated relative abundance in control treatment. CRA is the ratio of microbial abundance of nitrogen deposition to that of control. 


\section{Discussion}

Growing evidence shows that increased nitrogen deposition seriously affect the health and security of ecosystems (Ban et al., 2016; Meunier et al., 2016). For the YRD region, a sensitive coastal wetland ecosystem, the effects of ammonium and nitrate nitrogen deposition on methane emission were explored in this study. The findings demonstrated that ammonium nitrogen was a promoting factor for methane emission in the YRD. The research site was a methane source all year round for ammonium nitrogen deposition. Ammonium nitrogen providing not only an $\mathrm{N}$ resource, but also acting as an electron donor, may be the key.

Only abundances of Geobacillus and Clostridium increased after the addition of ammonium nitrogen (Fig. 4A), and there was a positive correlation between abundances of Geobacillus/Clostridium and ammonium nitrogen content (Fig. 4B). Previous study showed that degradation of macromolecular hydrocarbons by Geobacillus may even lead to an increase in methane production due to a direct interaction with methanogens (Miah et al., 2004). Some methanogenic archaea can get substrates or electrons from other symbiotic bacteria, such as Clostridium (Ban et al., 2016; Jain and Zeikus, 1989). Therefore, the microbial mechanism behind enhanced methane flux in the treatment of ammonium nitrogen deposition may be related to the cooperation of Geobacillus/Clostridium and methanogens in the YRD.

Ammonium nitrogen had a negative effect on Methanomassiliicoccaceae (Fig. 5B). Based on the reduced number of Methanomassiliicoccaceae, which was found mainly in the rumen (Henderson et al., 2016) and anaerobic digester (Gonzalez-Martinez et al., 2016), and obviously increased methane flux after addition of $\mathrm{NH}_{4} \mathrm{NO}_{3}$ (Fig 3A, and $\mathrm{B}$ ), it suggested that this kind of archaea may be not the key biogenic source for methane production. RDA analysis showed that ammonium nitrogen and Methanosarcinaceae were positive. It suggested that Methanosarcinaceae might have profited from ammonium supplementation. However, it was still relatively low $(0.13 \%)$ after application of $\mathrm{NH}_{4} \mathrm{Cl}$. It suggested that Methanosarcinaceae may contribute slightly to methane emissions during the wet season.

Apparently, Methanocellaceae was the most represented archaea during the wet season in the YRD with ammonium nitrogen deposition (Fig. 5A and B). It was consistent with a previous study that Methanocellaceae increased in abundance at the end after the alternate dry/wet cycles of paddy field soil (Ma et al., 2012). This coastal wetland is similar to paddy fields with alternating wet and dry environments. Thus, Methanocellaceae may be more viable than other methanogens in the YRD. According to the genome sequence of Methanocellaceae (Erkel et al., 2006), a unique set of genes encoding antioxidant enzymes and oxygen-insensitive fermentation enzymes were found, which probably improved their ability to adapt to alternate dry/wet conditions.

Although nitrate nitrogen may compete for electrons, which was crucial for methane production (Lai et al., 2016; Zhu et al., 2016), stimulation of plant growth by nitrate based fertilizers can enhance methane production by increased organic carbon availability for fermenting microbes delivering methanogenic substrates (Banger et al., 2012). Thus, the effects of nitrate nitrogen on methane emission were complicated. A wide range of influences may result in the slight difference between control and nitrate nitrogen deposition in this study.

According to RDA analysis, nitrate nitrogen appeared to have a similar influence tendency to ammonium nitrogen on bacterial diversity. An increase of measured ammonium nitrogen content may be part of the reason after the application of $\mathrm{KNO}_{3}$. However, there was a high negative correlation between nitrate nitrogen and potentially functional methanogen (Methanocellaceae). This may be the reason that $\mathrm{KNO}_{3}$ increased ammonium nitrogen content but did not have a significant effect on methane emissions.

\section{Conclusion}

Ammonium nitrogen deposition had more positive effect on methane emission than nitrate nitrogen. Ammonium nitrogen promoted methane emissions all year round. It suggested that decreasing the active ammonium nitrogen input may be more effective for slowing methane emissions in the YRD region. Methanocellaceae is the only methanogen with increased abundance after the application of $\mathrm{NH}_{4} \mathrm{Cl}$ and $\mathrm{NH}_{4} \mathrm{NO}_{3}$, which promoted methane emission, during the wet season. It indicated that this kind of methanogen may primarily contribute to methanogenesis with ammonium nitrogen enrichment in the YRD. Nitrate nitrogen did not affect methane flux to any significant extent. To the best of our knowledge, this study was the first to show that Methanocellaceae may be responsible for methane production in coastal wetland system. This study highlights the distinct impacts of ammonium and nitrate nitrogen on methane emission in the YRD and it will be helpful to understand the microbial mechanism responding to increased nitrogen deposition in the sensitive coastal wetland ecosystem.

\section{Conflict of interest}

The authors declare that they have no competing financial interest associated with this work.

\section{Acknowledgment}

This research was financially supported by the Projects of the National Natural Science Foundation of China (Grant nos. 41371257, 41573071 and 41205118), the Key Research Project of Frontier Science (No. QYZDJ-SSW-DQC015) of Chinese Academy of Sciences, Natural Science Foundation of Shandong Province (Grant no. ZR2016DQ12) and the Young Taishan Scholars Program (No. tsqn20161054) of Shandong Province.

\section{Appendix A. Supplementary data}

Supplementary data to this article can be found online at http://dx. doi.org/10.1016/j.scitotenv.2017.03.279.

\section{References}

Angel, R., Claus, P., Conrad, R., 2012. Methanogenic archaea are globally ubiquitous in aerated soils and become active under wet anoxic conditions. ISME J. 6, 847-862.

Asner, G.P., Townsend, A.R., Riley, W.J., Matson, P.A., Neff, J.C., Cleveland, C.C., 2001. Physical and biogeochemical controls over terrestrial ecosystem responses to nitrogen deposition. Biogeochemistry 54, 1-39.

Ban, S., Matsuda, K., Sato, K., Ohizumi, T., 2016. Long-term assessment of nitrogen deposition at remote EANET sites in Japan. Atmos. Environ. 146, 70-78.

Banger, K., Tian, H.Q., Lu, C.Q., 2012. Do nitrogen fertilizers stimulate or inhibit methane emissions from rice fields? Glob. Chang. Biol. 18, 3259-3267.

Bodelier, P.L.E., 2011. Interactions between nitrogenous fertilizers and methane cycling in wetland and upland soils. Curr. Opin. Environ. Sustain. 3, 379-388.

Bolger, A.M., Lohse, M., Usadel, B., 2014. Trimmomatic: a flexible trimmer for Illumina sequence data. Bioinformatics 30, 2114-2120.

DeSantis, T.Z., Hugenholtz, P., Larsen, N., Rojas, M., Brodie, E.L., Keller, K., et al., 2006 Greengenes, a chimera-checked 16S rRNA gene database and workbench compatible with ARB. Appl. Environ. Microbiol. 72, 5069-5072.

Edgar, R.C., Haas, B.J., Clemente, J.C., Quince, C., Knight, R., 2011. UCHIME improves sensitivity and speed of chimera detection. Bioinformatics 27, 2194-2200.

Erkel, C., Kube, M., Reinhardt, R., Liesack, W., 2006. Genome of Rice Cluster I archaea-the key methane producers in the rice rhizosphere. Science 313, 370-372.

Gomez-Casanovas, N., Hudiburg, T.W., Bernacchi, C.J., Parton, W.J., Delucia, E.H., 2016. Nitrogen deposition and greenhouse gas emissions from grasslands: uncertainties and future directions. Glob. Chang. Biol. 22, 1348-1360.

Gonzalez-Martinez, A., Garcia-Ruiz, M.J., Rodriguez-Sanchez, A., Osorio, F., GonzalezLopez, J., 2016. Archaeal and bacterial community dynamics and bioprocess performance of a bench-scale two-stage anaerobic digester. Appl. Microbiol. Biotechnol. 100, 6013-6033.

Gruber, N., Galloway, J.N., 2008. An Earth-system perspective of the global nitrogen cycle. Nature 451, 293-296.

Henderson, G., Cox, F., Ganesh, S., Jonker, A., Young, W., Janssen, P.H., et al., 2016. Rumen microbial community composition varies with diet and host, but a core microbiome is found across a wide geographical range (vol 5, 14567, 2015). Sci. Rep. 6. 
Hobbs, W.O., Lafrancois, B.M., Stottlemyer, R., Toczydlowski, D., Engstrom, D.R., Edlund, M.B., et al., 2016. Nitrogen deposition to lakes in national parks of the western Great Lakes region: isotopic signatures, watershed retention, and algal shifts. Glob. Biogeochem. Cycles 30, 514-533.

Jain, M.K., Zeikus, J.G., 1989. Bioconversion of gelatin to methane by a coculture of Clostridium collagenovorans and Methanosarcina barkeri. Appl. Environ. Microbiol. 55, 366-371.

Kanakidou, M., Myriokefalitakis, S., Daskalakis, N., Fanourgakis, G., Nenes, A., Baker, A.R., et al., 2016. Past, present, and future atmospheric nitrogen deposition. J. Atmos. Sci. 73 2039-2047.

Kruger, M., Frenzel, P., Conrad, R., 2001. Microbial processes influencing methane emission from rice fields. Glob. Chang. Biol. 7, 49-63.

Lai, C.Y., Wen, L.L., Shi, L.D., Zhao, K.K., Wang, Y.Q., Yang, X.E., et al., 2016. Selenate and nitrate Bioreductions using methane as the electron donor in a membrane biofilm reactor. Environ. Sci. Technol. 50, 10179-10186.

Liu, L.L., Greaver, T.L., 2009. A review of nitrogen enrichment effects on three biogenic GHGs: the $\mathrm{CO}_{2}$ sink may be largely offset by stimulated $\mathrm{N}_{2} \mathrm{O}$ and $\mathrm{CH}_{4}$ emission. Ecol. Lett. 12, 1103-1117.

Ma, K., Conrad, R., Lu, Y., 2012. Responses of methanogen mcrA genes and their transcripts to an alternate dry/wet cycle of paddy field soil. Appl. Environ. Microbiol. 78, 445-454.

Matson, P., Lohse, K.A., Hall, S.J., 2002. The globalization of nitrogen deposition: consequences for terrestrial ecosystems. Ambio 31, 113-119.

Meunier, C.L., Gundale, M.J., Sanchez, I.S., Liess, A., 2016. Impact of nitrogen deposition on forest and lake food webs in nitrogen-limited environments. Glob. Chang. Biol. 22, 164-179.

Miah, M.S., Tada, C., Sawayama, S., 2004. Enhancement of biogas production from sewage sludge with the addition of Geobacillus sp. strain AT1 culture. Jpn. J. Water Treat. Biol. 40, 97-104.

Ning, K., Yu, J., Qu, F., Wang, G., Guang, B., 2015. Atmospheric nitrogen deposition during growing season in coastal zone of the Yellow River Delta. Sci. Geogr. Sin. 32, 218-223.

Pakeman, R.J., Alexander, J., Brooker, R., Cummins, R., Fielding, D., Gore, S., et al., 2016. Long-term impacts of nitrogen deposition on coastal plant communities. Environ. Pollut. 212, 337-347.

Reyon, D., Tsai, S.Q., Khayter, C., Foden, J.A., Sander, J.D., Joung, J.K., 2012. FLASH assembly of TALENs for high-throughput genome editing. Nat. Biotechnol. 30, 460-465.
Sinsabaugh, R.L., Belnap, J., Rudgers, J., Kuske, C.R., Martinez, N., Sandquist, D., 2015. Soil microbial responses to nitrogen addition in arid ecosystems. Front. Microbiol. 6.

Sutton, M.A., Bleeker, A., 2013. Environmental science the shape of nitrogen to come. Nature 494, 435-437.

Wang, M., 2001. Methane Emission From Chinese Rice Paddies. Science Press.

Wang, Q., Garrity, G.M., Tiedje, J.M., Cole, J.R., 2007. Naive Bayesian classifier for rapid assignment of rRNA sequences into the new bacterial taxonomy. Appl. Environ. Microbiol. 73, 5261-5267.

Wang, Y.S., Wang, Y.H., 2003. Quick measurement of $\mathrm{CH}_{4}, \mathrm{CO}_{2}$ and $\mathrm{N}_{2} \mathrm{O}$ emissions from a short-plant ecosystem. Adv. Atmos. Sci. 20, 842-844.

Wolters, M.L., Sun, Z.C., Huang, C., Kuenzer, C., 2016. Environmental awareness and vulnerability in the Yellow River Delta: results based on a comprehensive household survey. Ocean Coast. Manag. 120, 1-10.

Yu, J., Fu, Y., Li, Y., Han, G., Wang, Y., Zhou, D., et al., 2011. Effects of water discharge and sediment load on evolution of modern Yellow River Delta, China, over the period from 1976 to 2009. Biogeosciences 8, 2427-2435.

Zhang, W., Cui, Y.H., Lu, X.K., Bai, E., He, H.B., Xie, H.T., et al., 2016. High nitrogen deposition decreases the contribution of fungal residues to soil carbon pools in a tropical forest ecosystem. Soil Biol. Biochem. 97, 211-214.

Zhang, Y., Yu, Q., Ma, W.C., Chen, L.M., 2010. Atmospheric deposition of inorganic nitrogen to the eastern China seas and its implications to marine biogeochemistry. J. Geophys. Res.-Atmos. 115.

Zheng, S., Zhang, H., Li, Y., Zhang, H., Wang, O., Zhang, J., et al., 2015. Co-occurrence of Methanosarcina mazei and Geobacteraceae in an iron (III)-reducing enrichment culture. Front. Microbiol. 6, 941

Zheng, X.H., Mei, B.L., Wang, Y.H., Xie, B.H., Wang, Y.S., Dong, H.B., et al., 2008. Quantification of $\mathrm{N}(2) \mathrm{O}$ fluxes from soil-plant systems may be biased by the applied gas chromatograph methodology. Plant Soil 311, 211-234.

Zhu, J, Wang Q, Yuan, M.D. Tan, G.Y.A. Sun, F.Q, Wang C. et al., 2016. Microbiology and potential applications of aerobic methane oxidation coupled to denitrification (AMED) process: a review. Water Res. 90, 203-215.

Zhu, M., Zhang, Z.H., Jun-Bao, Y.U., Li-Xin, W.U., Han, G.X., Yang, L.Q., et al., 2013. Effect of nitrogen deposition on soil respiration in Phragmites australis wetland in the Yellow River Delta, China. Chin. J. Plant Ecol. 37, 517-529. 